\title{
Seroprevalencia de Neospora caninum en bovinos de Lima y comparación entre ELISA e IFI
}

\author{
SEROPREVALENCE NEOSPORA CANINUM IN BOVINES OF LIMA AND COMPARISON BETWEEN \\ ELISA AND IFAT
}

\author{
Enrique Serrano-Martínez ${ }^{1,2}$, Roberto Evaristo R. ${ }^{1}$, Marco Quispe H. ${ }^{1}$, \\ Elizabeth Hinostroza M. ${ }^{1}$
}

\section{Resumen}

\begin{abstract}
El objetivo del estudio fue evaluar la prevalencia de anticuerpos frente a Neospora caninum en bovinos de establos de la cuenca lechera del departamento de Lima, Perú, y la concordancia entre dos técnicas diagnósticas empleadas para la detección de anticuerpos en suero: ensayo de inmunoabsorción ligado a enzimas (ELISA) e inmunofluorescencia indirecta (IFI). El estudio se realizó entre junio de 2015 y diciembre de 2016 en muestras de suero de 3407 bovinos lecheros provenientes de 101 establos de Lima (Barranca, Huaura, Huaral, Canta, Lima, Huarochirí, Cañete y Yauyos). La prevalencia de la infección a $N$. caninum fue de 31.0\% (1023/3407) obtenida por ELISA y 29.9\% (1018/3407) por IFI. La concordancia entre ambas técnicas diagnósticas fue buena $(\mathrm{K}=0.98)$ y estadísticamente significativa $(\mathrm{p}<0.001)$. Asimismo, 69 de los 101 establos resultaron positivos (68.3\%). Los resultados demostraron que los bovinos de establos lecheros de Lima tienen prevalencia individual moderada y alta prevalencia intra-rebaño frente a $N$. caninum.
\end{abstract}

Palabras clave: neosporosis; producción láctea; epidemiologia; IFI; ELISA

\section{AbSTRACT}

The objective of this study was to evaluate the prevalence of antibodies against Neospora caninum in dairy cattle farms of the department of Lima, Peru, and the conconrdance between two diagnostic techniques used for the detection of antibodies in serum: enzyme-linked immunosorbent assay (ELISA) and immunofluorescence antibody test (IFAT). The study was conducted between June 2015 and December 2016

\footnotetext{
${ }^{1}$ Facultad de Medicina Veterinaria y Zootecnia, Universidad Peruana Cayetano Heredia, Lima, Perú

${ }^{2}$ E-mail: enrique.serrano@upch.pe
}

Recibido: 26 de octubre de 2017

Aceptado para publicación: 15 de marzo de 2018 
in serum samples of 3407 dairy cattle from 101 farms in Lima (Barranca, Huaura, Huaral, Canta, Lima, Huarochirí, Cañete and Yauyos). The prevalence of infection to N. caninum was $31.0 \%(1023 / 3407)$ by ELISA and $29.9 \%(1018 / 3407)$ by IFAT. The concordance between both diagnostic techniques was good $(K=0.98)$ and statistically significant $(\mathrm{p}<0.001)$. Likewise, 69 of the 101 farms were positive $(68.3 \%)$. The results showed that cattle from Lima dairy farms have moderate individual prevalence and high intra-herd prevalence against $N$. caninum.

Key words: neosporosis; milk production; epidemiology, IFAT; ELISA

\section{INTRODUCCIÓN}

La neosporosis es una enfermedad cosmopolita que ocasiona importantes pérdidas económicas, afectando a una gran variedad de animales, principalmente a bovinos y es considerada como una de las principales causas de abortos a nivel mundial (Dubey, 2003). Neospora caninum es un parásito intracelular obligado que pertenece a la familia Apicomplexa, donde también se hallan los géneros Toxoplasma, Isospora y Sarcosystis, los cuales se diferencian por el tipo de huéspedes que intervienen durante su ciclo evolutivo (Dubey et al., 2007). La neosporosis es considerada una enfermedad importante debido a las infecciones reportadas en varios países, incluyendo Perú (Rivera et al., 2000).

El ciclo biológico se terminó de describir en 1998 al comprobarse que el perro era el hospedero definitivo (McAllister et al., 1998), siendo más susceptibles de presentar patologías neuromusculares los perros jóvenes (Knowler y Wheeler, 1995; Dubey y Lindsay, 1996). Por ello, la cercanía de estos con bovinos estabulados condiciona a la transmisión. La infección en caninos y bovinos ha sido reportada en varios países, pero con escasa manifestación neurológica (Dubey, 2003; Dubey et al., 2007; Dubey y Shares, 2011). En los estudios epidemiológicos realizados por Basso et al. (2001) se demostraron prevalencias variadas, donde los caninos de zonas urbanas presentaron menor infección comparado con aquellos de establos; asimismo refiere que la prevalencia aumenta cuando los canes proceden de establos con mayor casuística de abortos bovinos.

La infección por $N$. caninum se ha presentado en establos bovinos del Perú (Horna et al., 2003; Quevedo et al., 2003). La cuenca lechera de Lima no es ajena a los problemas reproductivos y la presencia de $N$. caninum, ya que ha sido demostrada en varios establos de Lima (Silva et al., 2002) desconociéndose la fuente de infección. Por otro lado, Rivera et al. (2000) reportaron que $62.1 \%$ de las vacas en Lima con antecedentes de aborto tenían anticuerpos antiNeospora caninum. Asimismo, Rivera (2001) reportó que $40 \%$ de los fetos bovinos abortados fueron positivos a este parásito.

Dubey et al. (1996) menciona que las técnicas serológicas de diagnóstico usadas para la detección de anticuerpos frente a este parásito son el ensayo por inmunoabsorción ligado a enzimas (ELISA), inmunofluorescencia indirecta (IFI), test de aglutinación para Neospora y Western Blot. El presente estudio tuvo como objetivo determinar la seroprevalencia de Neospora caninum en bovinos de establos lecheros de Lima, Perú, mediante las técnicas de ELISA e IFI, así como determinar la concordancia entre ambas técnicas. 


\section{Materiales y Métodos}

El estudio fue realizado en bovinos lecheros estabulados del valle de Lima, ubicado en la costa central del Perú. La zona se encuentra ubicada entre los 0 y los $500 \mathrm{msnm}$, de clima templado, con alta nubosidad en el invierno y humedad relativa de $75-80 \%$ (SENAMHI, 2016). El tamaño muestral fue calculado con base al censo del Instituto Nacional de Estadística e Informática (INEI, 2012).

Entre junio de 2015 y diciembre de 2016 fueron muestreados 3407 bovinos provenientes de 101 establos lecheros ubicados en el valle de Lima: Barranca (103), Huaura (581), Huaral (412), Canta (263), Lima (570), Huarochirí (446), Cañete (450) y Yauyos (582). Las muestras de sangre se extrajeron por punción de la vena yugular y se llevaron al Laboratorio de Parasitología Animal de la Facultad de Medicina Veterinaria y Zootecnia de la Universidad Peruana Cayetano Heredia, Lima, donde fueron centrifugadas a $1500 \mathrm{~g}$ por 5 minutos. El suero obtenido se colocó en microtubos de $1.5 \mathrm{ml}$ y se les mantuvo en congelación hasta su procesamiento.

La presencia de anticuerpos frente a $N$. caninum de determinó mediante la técnica de ELISA utilizando el kit comercial Neospora Ab Test (IDEXX, EEUU), considerando el protocolo del fabricante. La sensibilidad y especificidad de las pruebas es de 100 y $99.2 \%$, respectivamente. Los valores de la densidad óptica se midieron usando un espectrofotómetro de $650 \mathrm{~nm}$.

La detección de anticuerpos de $N$. caninum en suero se determinó, además, mediante la técnica del IFI. Se utilizó el antígeno de $N$. caninum $\left(10^{7} / \mathrm{ml}\right.$ taquizoítos formolados, cepa $\mathrm{NcSp} 7$ ), Anti IgG bovino marcado con isotiocianato de fluoresceína (VMRD, EEUU), en una dilución de 1:200. Asimismo, se utilizaron suero bovino control positivo y negativo a anticuerpos contra $N$. caninum. Para la interpretación se consideraron como muestras positivas al observarse el color fluorescente total del taquizoíto y negativas al carecer de fluorescencia o presentar fluorescencia parcial.

Los resultados de prevalencia se expresaron en forma porcentual. Se estimó la sensibilidad (S = VPI(VPI+FPI)*100), especificidad $(\mathrm{E}=\mathrm{VNI} /(\mathrm{FNI}+\mathrm{VNI}) * 100)$, valor predictivo positivo $(\mathrm{VPP}=\mathrm{VPI} /$ $(\mathrm{VPI}+\mathrm{FPI}) * 100)$ y valor predictivo negativo $(\mathrm{VPN}=\mathrm{VNI} /(\mathrm{FNI}+\mathrm{VNI}) * 100)$ de ambas técnicas, donde VPI y VNI $=$ verdaderos positivos y negativos a IFI, respectivamente, y FPI y FNI = Falsos positivos y negativos a IFI, respectivamente. Los resultados fueron categorizados como positivos y negativos en tabulación cruzada, y comparados por posibilidades de ser positivos mediante el test de kappa de Cohen (concordancia) con un nivel de significancia de $95 \%$. La técnica de ELISA fue considerada como «gold standard».

\section{Resultados}

La seropositividad de anticuerpos frente a $N$. caninum en bovinos provenientes del valle lechero de Lima fue de 31.0\% (1023/ 3407 ) mediante la técnica de ELISA y $29.9 \%$ (1018/3407) mediante IFI (Cuadro 1). De los 101 establos evaluados, 69 de ellos (68.3\%) presentaron bovinos con anticuerpos contra el parásito detectados por ambas pruebas serológicas. La concordancia entre las dos técnicas diagnósticas fue buena $(\mathrm{K}=0.98)$ y estadísticamente significativa $(\mathrm{p}<0.001)$ (Cuadro 2).

La sensibilidad de IFI fue $98.1 \%$ y la especificidad de 99.4\%. Los cálculos de sensibilidad, especificidad, valor predictivo positivo (VPP) y valor predictivo negativo (VPN) con $95 \%$ de intervalo de confianza se muestran en el Cuadro 3. 
Cuadro 1. Presencia de anticuerpos contra Neospora caninum en muestras de suero de bovinos del valle de Lima mediante las técnicas de ELISA e inmunofluorescencia indirecta (IFI)

\begin{tabular}{lccccc}
\hline \multirow{2}{*}{ Provincias } & $\begin{array}{c}\text { Muestras } \\
(\mathrm{n})\end{array}$ & \multicolumn{2}{c}{ ELISA } & \multicolumn{2}{c}{ IFI } \\
\cline { 3 - 6 } & & \multicolumn{2}{c}{ Muestras positivas } & \multicolumn{2}{c}{ Muestras positivas } \\
\cline { 3 - 6 } & 103 & 19 & $18.5 \pm 7.5$ & 17 & $16.5 \pm 7.2$ \\
\hline Barranca & 581 & 109 & $18.8 \pm 3.2$ & 103 & $17.7 \pm 3.1$ \\
Huaura & 412 & 104 & $25.2 \pm 4.2$ & 102 & $24.8 \pm 4.2$ \\
Huaral & 264 & 84 & $31.8 \pm 5.6$ & 81 & $30.7 \pm 5.6$ \\
Canta & 570 & 184 & $32.3 \pm 7.5$ & 182 & $31.9 \pm 7.5$ \\
Lima & 446 & 144 & $32.3 \pm 4.3$ & 146 & $32.7 \pm 4.4$ \\
Huarochirí & 450 & 186 & $41.3 \pm 4.6$ & 191 & $42.4 \pm 4.6$ \\
Cañete & 582 & 193 & $33.2 \pm 3.8$ & 196 & $33.7 \pm 3.8$ \\
Yauyos & 3407 & 1023 & $31.0 \pm 1.5$ & 1018 & $29.9 \pm 1.5$ \\
\hline Total & & & & & \\
\hline
\end{tabular}

Cuadro 2. Comparación de resultados positivos a $N$. caninum de muestras de suero de bovinos del valle de Lima, mediante las técnicas de ELISA e inmunofluorescencia indirecta (IFI)

\begin{tabular}{lccc}
\hline \multirow{2}{*}{ ELISA } & \multicolumn{2}{c}{ IFI } & \multirow{2}{*}{ Total } \\
\cline { 2 - 3 } & Positivo & Negativo & \\
\hline Positivo & 1003 & 20 & 1023 \\
Negativo & 15 & 2369 & 2384 \\
\hline Total & 1018 & 2389 & 3407 \\
\hline$(\mathrm{K}=0.98)$ & & &
\end{tabular}

\section{Discusión}

La seroprevalencia del protozoario Neospora caninum en ganado bovino lechero ha sido estudiado en diversas partes del mundo (Huong et al., 1998; Bae et al., 2000; Ooi et al. 2000), así como su importancia como agente causal de abortos en bovinos (Gondim et al., 1999; Atkinson et al. 2000). La cuenca lechera de Lima es una de las principales fuentes de abastecimiento de productos lácteos del Perú, y el presente estudio reveló una prevalencia anti- $N$. caninum de $31.0 \%$ (1023/3407) en sueros bovinos provenientes de 101 establos lecheros mediante la prueba de ELISA y 29.8\% (1018/3407) mediante la técnica de IFI, además de una seroprevalencia intra-rebaño de $68.3 \%(69 / 101)$ mediante ambas técnicas. Estos resultados demuestran que la seroprevalencia frente a $N$. caninum en los establos lecheros de Lima es moderada de manera individual y alta a nivel intra-rebaño.

Davison et al. (1999) evaluaron en el Reino Unido mediante la prueba de ELISA a 372 vacas con terneros neonatos previos a la ingesta de calostro, encontrando 124 vacas y 188 terneros seropositivos a $N$. caninum, dando una probabilidad de trasmisión vertical de $95.2 \%$. Estos resultados revelan que las vacas seropositivas tienen mayor probabilidad de producir terneros infectados y perpetuar la infección del hato. 
Cuadro 3. Resultados de sensibilidad, especificidad, valor predictivo positivo y negativo mediante las técnicas de ELISA como gold standard e inmunofluorescencia indirecta (IFI) en muestras de bovino del valle de Lima

\begin{tabular}{cccccc}
\hline Técnicas & $\begin{array}{c}\text { Seroprevalencia } \\
(95 \% \mathrm{IC})\end{array}$ & $\begin{array}{c}\text { Sensibilidad } \\
(\%) \\
(95 \% \mathrm{IC})\end{array}$ & $\begin{array}{c}\text { Especificidad } \\
(\%) \\
(95 \% \mathrm{IC})\end{array}$ & $\begin{array}{c}\mathrm{VPP}^{1}(\%) \\
(95 \% \mathrm{IC})\end{array}$ & $\begin{array}{c}\mathrm{VPN}^{2}(\%) \\
(95 \% \mathrm{IC})\end{array}$ \\
\hline ELISA & $\begin{array}{c}31.0 \\
(29.5-32.6)\end{array}$ & 100 & 100 & 100 & 100 \\
IFI & $\begin{array}{c}29.9 \\
(28.3-31.4)\end{array}$ & $\begin{array}{c}98.1 \\
(96.5-99.6)\end{array}$ & $\begin{array}{c}99.4 \\
(97.8-100)\end{array}$ & $\begin{array}{c}98.5 \\
(97.0-100)\end{array}$ & $\begin{array}{c}99.2 \\
(97.6-100)\end{array}$ \\
\hline
\end{tabular}

${ }^{1}$ Valor predictivo positivo

${ }^{2}$ Valor predictivo negativo

Los resultados confirman la presencia continuada de $N$. caninum en el departamento de Lima. En estudios en otras localidades, como en Chachapoyas en bovinos lecheros de crianza extensiva mayores de dos años se encontró 40.4\% (107/265) de seropositividad a este parásito mediante IFI (Quevedo et al., 2003), mientras en Junín, utilizando la misma técnica, se encontró $12.8 \pm 3.5 \%(45 / 347)$ de prevalencia (Puray et al., 2006).

$N$. caninum tiene un gran impacto a nivel mundial. Gondim et al. (1999) reportaron una prevalencia de $14.1 \%$ en 447 bovinos en Bahia, Brasil; Campero et al. (1998) encontró una seroprevalencia de $56.9 \%$ en Argentina; Buxton et al (1997) señalaron una seroprevalencia de $59 \%$ en vacas con historias de abortos en Escocia; Ooi et al. (2000) encontraron $44.9 \%$ de anticuerpos positivos a $N$. caninum en Taiwán; y Atkinson et al. (2000) reportaron $24 \%$ de seroprevalencia en 266 bovinos lecheros en Australia tras un periodo de abortos. Todos los resultados mencionados fueron determinados a través de IFI. Por otro lado, estudios realizados mediante la técnica de ELISA por Kowalczyk et al. (2016) en 97 hatos lecheros en Polonia reportaron una prevalencia de $56.7 \%$ (56/97) frente a $N$. caninum; en tanto que Enachescu et al. (2014) reportaron en el sur de Rumanía seroprevalencias de $N$. caninum de $45 \mathrm{y}$ $56.8 \%$, utilizando dos kits comerciales de ELISA. Estos resultados demuestran que el parásito es cosmopolita y la prevalencia es mayor en el ganado lechero por el propósito y tiempo de vida.

\section{ConClusiones}

- Se encontró una prevalencia individual moderada de anticuerpos frente a $N$. caninum de $31.0 \pm 1.5 \%$ mediante la técnica de ELISA y $29.8 \pm 1.5 \%$ mediante la técnica de IFI en 3407 bovinos de propósito lechero de Lima, Perú.

- La concordancia diagnóstica entre las técnicas serológicas ELISA e IFI frente a $N$. caninum en bovinos es buena $(\mathrm{K}=0.98)$.

- Se encontró una prevalencia intra-rebaño alta de anticuerpos frente a $N$. caninum (68.3\%; 69/101) mediante las técnicas de ELISA e IFI.

\section{Agradecimientos}

Los autores agradecen el financiamiento del estudio al Fondo para la Innovación, Ciencia y Tecnología (FINCyT-Innóvate Perú), 
Proyecto «Obtención y caracterización del primer aislado de Neospora caninum causante de abortos y mortalidad neonatal en la producción bovina lechera del Perú, con fines inmunodiagnóstico y vacunal» (Contrato 167-PNICP-PIAP-2015 FINCYT); al Programa Iberoamericano de Ciencia y Tecnología para el Desarrollo (CYTED) por el apoyo financiero brindado a la Red Temática 113RT0469 PROTOZOOVAC: «Diagnóstico y control de las protozoosis reproductivas del ganado bovino» que permitió la capacitación técnica de los investigadores para la ejecución del estudio. Del mismo modo, al Dr. Luis Miguel Ortega-Mora y al Grupo SALUVET de la Universidad Complutense de Madrid, España, por la donación de la cepa de Neospora caninum (NcSp7).

\section{Literatura Citada}

1. Atkinson RA, Cook RW, Reddacliff LA, Rothwell J, Broady KW, Harper P, Ellis JT. 2000. Seroprevalence of Neospora caninum infection following an abortion outbreak in dairy cattle herd. Aust Vet J 78: 262-266. doi: 10.1111/ j.1751-0813.2000.tb11752.x

2. Bae JS, Kim DY, Hwang WS, Kim JH, Lee NS, Nam HW. 2000. Detection of IgG antibody against Neospora caninum in cattle in Korea. Korean J Parasitol 38: 245-249.

3. Basso W, Venturini L, Venturini $C$, Moore P, Rambeau M, Unzaga J.M, Campero $C$, et al. 2001. Prevalence of Neospora caninum infection in dogs from beef-cattle farms, dairy farms, and urban areas of Argentina. J Parasitol 87: 906-907. doi: 10.1645/0022-3395(2001)087[0906:PONCII]2.0.CO;2

4. Davison HC, Otter A, Trees AJ. 1999. Estimation of vertical and horizontal transmission parameters of Neospora caninum infections in dairy cattle. Int $\mathrm{J}$ Parasitol 29: 1683-1689.
5. Dubey J, Lindsay DS. 1996. A review of Neospora caninum and neosporosis. Vet Parasitol 67: 1-59. doi: 0.1016/S03044017(96)01035-7

6. Dubey J, Schares G, Ortega-Mora L. 2007. Epidemiology and control of neosporosis and Neospora caninum. Clin Microbiol Rev 20: 323-367. doi: 10.1128/CMR.00031-06

7. Dubey J. 2003. Review of Neospora caninum and neosporosis in animals. Korean J Parasitol 41: 1-16. doi: 10.3347/ kjp.2003.41.1.1

8. Enachescu V, Ionita M, Miltrea L. 2014. Comparative study for the detection of antibodies to Neospora caninum in mild and sera in dairy cattle in southern Romania. Acta Parasitol 59: 5-10. doi: 10.2478/s11686-014-0202-x

9. Gondim LF, Sartor IF, Hasegawa M, Yamane I. 1999. Seroprevalence of Neospora caninum in dairy cattle in Bahia, Brazil. Vet Parasitol 86: 71-75.

10. Horna S, Chávez A, Casas E, Serrano-Martínez E. 2003. Seroporevalencia de Neospora caninum en caninos de dos distritos de la provincia de Chachapoyas. Rev Inv Vet Perú 14: 150-154. doi: 10.15381/rivep.v14i2.1620

11. Huong LT, Ljungstrom BL, Uggla A, Bjorkman C. 1998. Prevalence of antibodies to Neospora caninum and Toxoplasma gondii in cattle and water buffaloes in southern Vietnam. Vet Parasitol 75: 53-57. doi: 10.1016/S03044017(97)00178-7

12. [INEI] Instituto Nacional de Estadística e Informática. 2012. IV Censo Nacional Agropecuario 2012. [Internet]. Disponible en: http://censos.inei.gob.pe/ cenagro/tabulados/?id=Censos Nacionales

13. Knowler C, Wheeler S. 1995. Neospora caninum infection in three dogs. J Small Anim Pract 36: 172-177. doi: 10.1111/j.1748-5827.1995.tb02875.x

14. Kowalczyk S, Czopowicz M, Weber C, Müller E, Witkowsi E, Kaba J. 2016. Herd-level seroprevalence of Neospora 
caninum infection in dairy cattle in central and northeastern Poland. Acta Parasitol 61: 63-65. doi: 10.1515/ap-20160006

15. McAllister M, Dubey J, Lindsay D, Jolley WR, Wills R, McGuire A. 1998. Dogs are definitive hosts of Neospora caninum. Int J Parasitol 28: 1473-1478. doi: 10.1016/S0020-7519(98)00138-6

16. Ooi HK, Huang CH, Yang S, Lee H. 2000. Serological survey and first finding of Neospora caninum in Taiwan, and the detection of this antibodies in various body fluids of cattle. Vet Parasitol 90: 47-55. doi: 10.1016/S0304-4017(00)00211-9

17. Puray N, Chávez A, Casas E, Falcón N, Casas G. 2006. Prevalencia de Neospora caninum en bovinos de una empresa ganadera de la sierra central del Perú. Rev Inv Vet Perú 17: 189-194. doi: 10.15381/rivep.v17i2.1542
18. Quevedo J, Chávez A.; Rivera $\mathrm{H}, \mathrm{Ca}$ sas E, Serrano-Martínez E. 2003. Neosporosis en bovinos lecheros en dos distritos de la provincia de Chachapoyas. Rev Inv Vet Perú 14: 33-37. doi: 10.15381/rivep.v14i1.1594

19. Rivera H, Nelson D, Tabacchi L. 2000. Neospora caninum y otros agentes en fetos abortados de bovinos lecheros del valle de Lima. Rev Inv Vet Perú 11(1): 1-7. doi: 10.15381/rivep.v11i1.6766

20. Rivera H. 2001. Causas frecuentes de aborto bovino. Rev Inv Perú 12(2):117122.

21. [SENAMHI] Servicio Nacional de Meteorología e Hidrología del Perú. 2016. Pronósticos climáticos. [Internet]. Disponible en: http://www.senamhi.gob.pe/main_mapa.-php? $\mathrm{t}=\mathrm{dHi}$

22. Silva P, Chávez A, Rivera H, Casas E. 2002. Seroprevalencia de Neospora caninum en bovinos lecheros del valle de Lima. Rev Inv Vet Perú 13(2): 5155. doi: 10.15381/rivep.v13i2.7330 